\title{
Retrieval from iconic memory with shape as the selection criterion $^{1}$
}

\author{
M. T. TURVEY ${ }^{2}$ AND S. KRAVETZ \\ UNIVERSITY OF CONNECTICUT
}

Selection of items from iconic memory on the basis of shape was studied by means of the Sperling (1960) partial report procedure. The results indicated that partial report by shape was superior to whole report, that partial report by location was superior to partial report by shape, and that the accuracy of report as a function of delay of indicator declined at the same rate for selection by shape and selection by location. The results were discussed in the framework of the flow of visual information within $S$.

In the general information-processing model of visual perception (see Haber, 1969), it is suggested that visual information can be stored for several hundred milliseconds in a literal, labile form prior to transfer to a more limited but more persistent categorical memory system. Neisser (1967) has applied the term 'iconic memory' to the initial register of visual information.

In his seminal work on iconic memory Sperling (1960) presented S tachistoscopically with an array of either letters or digits followed by an indicator cueing $S$ to report a particular part of the array. This partial report procedure enabled Sperling to demonstrate that $S$ has far more information available than can be reported by the memory span, or whole report, technique. However, with increase in the delay of the tone indicator, the superiority of the partial report over the whole report declined, suggesting the rapid decay character of iconic memory. In all but one of Sperling's experiments the postdelay signal directed $S$ 's report to a row or a column. In one experiment, however, Sperling used a stimulus array consisting of letters and digits intermixed and cued for report by category (e.g., letters) rather than by location (e.g., row) as was the case in the other experiments. With the indicator signaling report by category, partial report was not superior to whole report. It now seems clear, however, that Sperling's failure to demonstrate efficient selection by category was due to the considerable time required to categorize a particular set of physical characteristics as representing an item belonging to the class 'letters' or the class 'digits' (cf. Posner \& Mitchell, 1967). As a general principle it may be stated that the longer the time required to select items according to a particular criterion, the less available is the information in iconic memory and the less likely is it that partial report will be superior to whole report. Presumably if selection from iconic memory is based upon criterion features already discriminated at the level of iconic memory then efficient selection by category would be possible.

Two recent experiments have shown that selection from iconic memory by category is efficient when the categories are describable in physical terms as opposed to 'symbolic.' Von Wright (1968) demonstrated superior partial report over whole report when selection from iconic memory was by chromatic color, achromatic color, and size, and Clark (1969) similarly demonstrated efficient selection by chromatic color. In the Clark experiments, however, it was observed that recall by color category did not decline as a function of delay in the postdisplay tone indicator whereas such a decline did obtain when selection from the same displays was by location. Clark's data therefore suggest that the decay function of iconic memory is dependent on the retrieval task demanded of $S$. When $S$ is required to select by location, recall declines as a function of delay of the cue; such is not the case, however, for recall when selection is by category. Von Wright's experiment sheds no light on this seemingly paradoxical observation of Clark since his experiment studied partial report by category at only one delay of indicator interval, $5 \mathrm{msec}$.

The purpose of the present experiment was twofold. First, to explore further the list of physical features on the basis of which items can be selected from iconic memory. Since the experiments of Sperling, Von Wright, and Clark have shown that items can be selected efficiently on the basis of location, color, brightness, and size, one should likewise be able to demonstrate efficient selection on the basis of shape. Second, to test the inference from Clark's data that selection by category results in a different partial report by delay of indicator function than selection by location. If Clark's data reflect a general principle then there should be an interaction between mode of selection, i.e., selection by shape and selection by location, and delay of the indicator.

\section{METHOD}

Subjects

The Ss were six undergraduates from the University of Connecticut who participated in the experiment as part of a course requirement.

\section{Materials and Apparatus}

Three shapes were used, which were the three letters $R, O$, and $Z$. Forty slides were constructed with three rows of four letters. In each slide the three letters each appeared four times. Each of the 403 by 4 matrices was generated by random selection without replacement from the set of 12 items.

A Lafayette T-2K constant illumination projecting tachistoscope was used to project the stimulus slide onto the viewing screen. The presented field subtended a visual angle of $2 \mathrm{deg} 24 \mathrm{sec}$ vertical by $3 \mathrm{deg} 20 \mathrm{sec}$ horizontal at a viewing distance of $7 \frac{1}{2} \mathrm{ft}$. One channel constantly projected a darkened preexposure field to reduce brightness contrast. The center of the preexposure field was marked by a faint but discernible cross. The duration of the display was $100 \mathrm{msec}$. In the partial report conditions the display was followed by one of three possible tones at one of three possible intervals. The delay intervals were 0,500 , and $1000 \mathrm{msec}$, and the tones were delivered to $\mathrm{S}$ by means of earphones. The exposure duration, tone delay, and tone duration were controlled by three Hunter timers.

\section{Procedure}

For any trial the general procedure was as follows: $S$ was instructed to view the cross until it appeared in focus; $S$ then pressed a key that initiated the display. $S$ recorded his report on a response grid using a separate response grid for each trial. In the partial report conditions a tone indicator followed the display at a predetermined interval cueing $S$ to report jtems on the basis of row or shape. In the whole report condition no tone was presented after the display; on termination of the display $S$ attempted to report as many items as possible. Each $S$ on each trial was scored in terms of the number of letters reported in the correct position. For the partial report conditions the proportion of correctly recalled letters out of all letters in the row or category to be selected was multiplied by the total 
number of letters, i. e., 12 , in the matrix (see Sperling, 1960).

Each $S$ was given 3 days of preexperimental training. The first day was primarily concerned with establishing the postdisplay indicator tones and orienting $S$ to the procedure. The tones were designated as high, middle, and low corresponding to the three rows of the display or the letters $R, O$, and $Z$, respectively. On Day $1 \mathrm{~S}$ received 20 trials of partial report by row (PRR), 12 trials of whole report (WR), and 20 trials of partial report by shape (PRS).

On Day 2 the six Ss received 12 trials WR, 36 trials PRS, and finally another 12 trials WR. Day 3 was the same as Day 2 except the 36 trials PRS preceded the 36 trials PRR. Days 4 and 5 were the experimental days. On Day 4 Ss $1-3$ were given 12 trials WR, 72 trials PRR, 12 trials WR, in that order. Ss 4-6 were given 12 trials WR, 72 trials PRS, 12 trials WR in that order. Five minutes rest period elapsed between each set of trials. On Day 5 Ss 4-6 received the Day 4 trial sequence of Ss 1-3 who in turn received the Day 4 trial sequence of Ss 4-6.

Throughout the training and experimental days the tone-row and tone-shape combinations were counterbalanced so that each tone specified each row and each shape an equal number of times at each delay interval. Furthermore, although slides were repeated on training and experimental days, previous research (Sperling, 1960; Turvey, 1967) suggests that repetition of displays in the Sperling situation does not result in the 'learning' of those displays to any significant degree.

\section{RESULTS AND DISCUSSION}

Figure 1 represents the percent recall and the number of items recalled as a function of the delay in the postdisplay indicator for selection by location and selection by shape. Figure 1 also includes the immediate memory span (whole report) base line. It is clear from inspection of Fig. 1 that partial report by either location or shape was superior to whole report. In Sperling's (1960) experiments it was observed that partial report was no longer superior to whole report at $1000 \mathrm{msec}$. The present experiment, however, clearly indicates that partial report was superior to whole report for both modes of selection at the longest delay of $1000 \mathrm{msec}$, an observation congruent with Clark (1969).

The total number of letters correctly recalled at each delay interval by each $S$ for

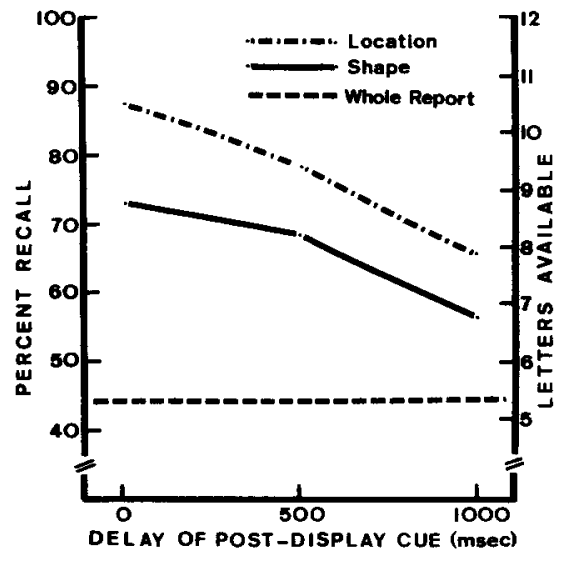

Fig. 1. Percentage recall and the number of items recalled as a function of the delay of indicator for selection by location and selection by shape.

both selection by location (row) and selection by category (shape) were cast into a Treatment (basis of selection) by Treatment (delay) by $S s$ analysis of variance. The analysis revealed that the main effect of selection criterion was significant, $F(1,5)=7.99, p<.05$ as was the main effect of delay, $F(2,10)=29.19$, $p<.001$. The interaction between selection criterion and delay was, however, insignificant, $F(2,10)=2.37, \mathrm{p}>.05$.

Concerning the two questions to which the present experiment addressed itself, it is clear that $\mathbf{S}$ can select items efficiently from iconic memory on the basis of shape, and that the rate of information loss from iconic memory does not vary as a function of whether $S$ selects on the basis of shape or on the basis of location. In regards to the superiority of selection by location over selection by shape note the following. Although $S$ had to identify different letters in partial report by location (row), the number of possible locations for each reported letter in the row is low compared to the number of possible locations for the reported letter shape in the partial report by shape condition. It appears that the greater uncertainty of location in the report by shape condition was more detrimental than the greater uncertainty of item in the report by row condition. ${ }^{3}$ There is evidence in Clark's data that, although report by location declined as a function of delay of indicator and report by color did not, report by location yielded higher levels of recall than report by color. The absence of an interaction between mode of selection and delay of indicator in the present experiment suggests, however, that Clark's experiments do not reflect a property specific to report by category but rather reflect some property of organization or encoding of color information in iconic memory. As to what this property might be remains somewhat unclear at the present.

In summary, the present experiment indicates that selection by shape is an effective means of processing information in iconic memory. In regards to the general model of the flow of information within $S$, the present data support the notion that the first stage involves the storage of items discriminated in accordance with their physical characteristics. The present data together with those reported by Von Wright and Clark demonstrate that Ss are able to select or ignore items in iconic memory on the basis of their general physical features. As Sperling (1960) has previously demonstrated, Ss cannot select letters or digits from an array of letters and digits in the same efficient manner, suggesting that such properties are not identified at the level of iconic memory.

\section{REFERENCES}

CLARK, S. E. Retrieval of color information from preperceptual memory. Journal of Experimental Psychology, 1969, 82, 263-266.

HABER, R. N. Information processing analyses of visual perception: An introduction. In R. N. Haber (Ed.), Information processing approaches to visual perception. New York: Holt, Rinehart, \& Winston, 1969. Pp. 1-15.

NEISSER, U. Cognitive psychology. New York: Appleton-Century-Crofts, 1967.

POSNER, M. I., \& MITCHELL, R. F. Chronometric analysis of classification. Psychological Review, 1967, 74, 392-409.

SPERLING, G. The information available in brief visual presentations. Psychological Monographs, 1960, 74 (Whole No. 498).

TURVFY, M. T. Repetition and the preperceptual information store. Journal of Experimental Psychology, 1967, 74, 289-293.

VON WRIGHT, J. M. Selection in visual immediate memory. Quarterly Journal of Experimental Psychology, 1968, 20, 62-68.

\section{NOTES}

1. This research was supported by research grant No. 102 from the University of Connecticut Research Foundation to the senior author.

2. Address: Department of Psychology, University of Connecticut, Storrs, Connecticut 06268

3. For further discussion of the superiority of report by location over report by category, see Von Wright (1968).

(Accepted for publication November 19, 1969). 